\title{
A Closure Study of Total Scattering Using Airborne In Situ Measurements from the Winter Phase of TCAP
}

\author{
Evgueni Kassianov ${ }^{1, *}$, Larry K. Berg ${ }^{1}$, Mikhail Pekour ${ }^{1}$, James Barnard ${ }^{2}$, Duli Chand ${ }^{1}$, \\ Jennifer Comstock ${ }^{1}$, Connor Flynn ${ }^{1}$, Arthur Sedlacek ${ }^{3}$, John Shilling ${ }^{1}$ (i), Hagen Telg ${ }^{4}$ (i), \\ Jason Tomlinson ${ }^{1}$, Alla Zelenyuk ${ }^{1}{ }^{1}$ and Jerome Fast ${ }^{1}$ \\ 1 Pacific Northwest National Laboratory, Richland, WA 99352, USA; Larry.Berg@pnnl.gov (L.K.B.); \\ Mikhail.Pekour@pnnl.gov (M.P.); Duli.Chand@pnnl.gov (D.C.); Jennifer.Comstock@pnnl.gov (J.C.); \\ Connor.Flynn@pnnl.gov (C.F.); John.Shilling@pnnl.gov (J.S.); Jason.Tomlinson@pnnl.gov (J.T.); \\ Alla.Zelenyuk-imre@pnnl.gov (A.Z.); Jerome.Fast@pnnl.gov (J.F.) \\ 2 Department of Physics, University of Nevada, Reno, NV 89557, USA; jbarnard@unr.edu \\ 3 Brookhaven National Laboratory, Upton, NY 11973, USA; sedlacek@bnl.gov \\ 4 Cooperative Institute for Research in Environmental Sciences (CIRES), University of Colorado, Boulder, \\ CO 80309; USA; hagen.telg@noaa.gov \\ * Correspondence: Evgueni.Kassianov@pnnl.gov; Tel.: +1-509-372-6535
}

Received: 8 May 2018; Accepted: 8 June 2018; Published: 12 June 2018

\begin{abstract}
We examine the performance of our approach for calculating the total scattering coefficient of both non-absorbing and absorbing aerosol at ambient conditions from aircraft data. Our extended examination involves airborne in situ data collected by the U.S. Department of Energy's (DOE) Gulf Stream 1 aircraft during winter over Cape Cod and the western North Atlantic Ocean as part of the Two-Column Aerosol Project (TCAP). The particle population represented by the winter dataset, in contrast with its summer counterpart, contains more hygroscopic particles and particles with an enhanced ability to absorb sunlight due to the larger fraction of black carbon. Moreover, the winter observations are characterized by more frequent clouds and a larger fraction of super-micron particles. We calculate model total scattering coefficient at ambient conditions using size spectra measured by optical particle counters (OPCs) and ambient complex refractive index (RI) estimated from measured chemical composition and relative humidity (RH). We demonstrate that reasonable agreement ( $20 \%$ on average) between the observed and calculated scattering can be obtained under subsaturated ambient conditions $(\mathrm{RH}<80 \%)$ by applying both screening for clouds and chemical composition data for the RI-based correction of the OPC-derived size spectra.
\end{abstract}

Keywords: aircraft measurements of aerosol microphysical; chemical, and optical components and ambient relative humidity; ultra-high sensitivity aerosol spectrometer (UHSAS); passive cavity aerosol spectrometer (PCASP); cloud and aerosol spectrometer (CAS); aerosol mass spectrometer (AMS); single particle soot photometer (SP2); single particle mass spectrometer (miniSPLAT); integrating nephelometer; humidification system; winter phase of Two-Column Aerosol Project (TCAP)

\section{Introduction}

There is an increasing demand to better understand the role of atmospheric aerosol in the Earth's radiation budget over a range of seasons [1,2]. However, strong spatial-temporal variability of aerosol properties associated with variety of natural and anthropogenic sources $[3,4]$ is responsible for large uncertainties of predicted aerosol radiative forcing at global and local scales [5,6]. This variability is especially well-pronounced for coastal areas, which typically represent crossroads of distinct air-mass flow patterns [7-9]. For example, Titos et al. [8] analyzed near-surface aerosol total scattering 
coefficients from approximately one year of measurements made at Cape Cod, Massachusetts as part of the Two-Column Aerosol Project (TCAP) campaign [10,11] and demonstrated that there were three major groups of air masses. These groups have been classified as "anthropogenic", "marine", and "hybrid" air-masses in terms of scattering Angstrom exponent (AE). The "anthropogenic" and "marine" air-masses have large $(1.8 \pm 0.5)$ and small $(0.9 \pm 0.3)$ values of $\mathrm{AE}$, respectively [8]. Since the AE is related inversely to particle size [12], the "anthropogenic" and "marine" air-masses are dominated by relatively small and large particles, respectively. It is quite interesting that the "anthropogenic" air-mass patterns have been more frequently observed during summer, while their "marine" counterparts were common during winter [10,11]. The TCAP provided a unique opportunity to characterize aerosol physical, chemical and optical properties at the site during summer and winter, and thus to document strong seasonal changes of these properties [10,11].

These properties have been obtained from integrated data provided by a suite of TCAP ground-based and airborne instruments with different design and sensitivity to particle size $[10,11]$. Thus, successful data integration is a difficult task with far-reaching impacts on further process-oriented model evaluations. This is especially true for airborne measurements mainly due to well-known stringent requirements for the high-resolution data acquisition by a compact and multiple-variable aircraft system [13,14]. Typically, a special kind of quantitative comparison experiment-as it traditionally referred to as a closure study-is performed to assess the consistency and reasonableness of integrated data [15-18]. We have previously performed a closure study of ambient total scattering coefficient using integrated TCAP data collected by the U.S. Department of Energy's (DOE) Gulfstream 1 (G-1) aircraft over Cape Cod and the western North Atlantic Ocean during summer and obtained good agreement ( $10 \%$ on average) between the measured and calculated total scattering coefficients for mostly clear-sky conditions with high concentration of small particles [19].

In comparison with summer, winter represents more challenging observational conditions for such a comparison because: (1) more frequent cloudy days, which increases the variability of the observed scattering coefficients; and (2) increased fraction of large particles, which have often been ignored in the closure studies due to limited information on their chemical composition. With this challenge in mind, we attempt to address the following question: What level of agreement between the measured and calculated total scattering coefficients can be achieved for challenging wintertime conditions?

To answer this question, we first describe the airborne in situ data collected during winter campaign that provide information on aerosol chemical, microphysical, and optical properties. We do that with a particular focus on the cloud contamination issue and the required cloud screening application (Section 2). Also, our study aims to illustrate the differences between the airborne in situ data collected during summer [19] and winter (this study), which in turn defines seasonal diversity between the corresponding microphysical and optical aerosol properties (Section 3) in the context of the closure study (Section 4). Ambient size distribution and complex refractive index are examples of key aerosol properties for the closure study. The latter are required to calculate the ambient total scattering coefficient over the variety of observational conditions (Section 4). Comparison of the calculated and observed ambient total scattering coefficients is considered as part of the closure study (Section 4) with an overall goal to illustrate the consistency and reasonableness of the wintertime airborne in situ data. To ease comparison of the outlined seasonal changes of the microphysical, chemical, and optical aerosol properties (winter versus summer), we use the same format for our winter plots (Sections 2-4) identical to that for the corresponding summer plots [19]. Our main findings are summarized in the last section.

\section{Data}

All data used here were collected on the G-1 aircraft during the TCAP winter aircraft intensive observation period (12-26 February 2013) [11]. The collected data represent mostly background coastal conditions. The instruments, with state-of-the-art capabilities [13], sampled climate-relevant atmospheric characteristics, such as relative humidity $(\mathrm{RH})$, and aerosol and cloud properties, with high 
temporal resolution ( $1 \mathrm{~s}$ ) at multiple altitudes within two atmospheric columns (over the Cape Cod and over the Atlantic Ocean) separated by several hundred kilometers. Here we consider only winter aerosol properties relevant to our closure study (Section 4)—namely aerosol size spectra, chemical composition, and total scattering coefficient-and describe shortly the corresponding instruments. Their detailed review is given by Berg et al. [10]. Similar to the previous studies [20,21], we use the high-temporal resolution data to calculate the aerosol properties for a straight and level runs at different altitudes, the co-called flight legs (FLs). The FLs ranged from approximately 5 to $15 \mathrm{~min}$ in duration and may include periods when the G-1 was in cloud. Thus, special attention is given to the problem of potential cloud contamination and the removal of identified cloud-contaminated airborne data from further analysis.

Ultra-high sensitivity aerosol spectrometer (UHSAS, size range $0.06-1 \mu \mathrm{m}$ ), a passive cavity aerosol spectrometer (PCASP; size range $0.13-3 \mu \mathrm{m}$ ), and a cloud and aerosol spectrometer (CAS; size range $0.6-10 \mu \mathrm{m}$ ) were used to measure individual particle size distributions for different and partially overlapping size ranges. These three airborne instruments are optical particle counters (OPCs) and they are made by Droplet Measurement Technologies, Inc. (Longmont, CO, USA). Calibration of these instruments involves use of non-absorbing polystyrene latex sphere (PSL) beads with known real part (1.588) of complex refractive index (RI). To obtain combined aerosol size spectra over a wide size range $(0.06-10 \mu \mathrm{m})$, size distributions measured by UHSAS, PCASP, and CAS are merged using the well-documented Twomey's algorithm [22,23]. Figure 1 shows an example of the merged aerosol size spectra for a given day of interest (25 February 2013). The obtained size spectra are FL-dependent and there are clearly two groups of spectra with relatively small and large contributions of super- $\mu \mathrm{m}$ particles (Figure 1).

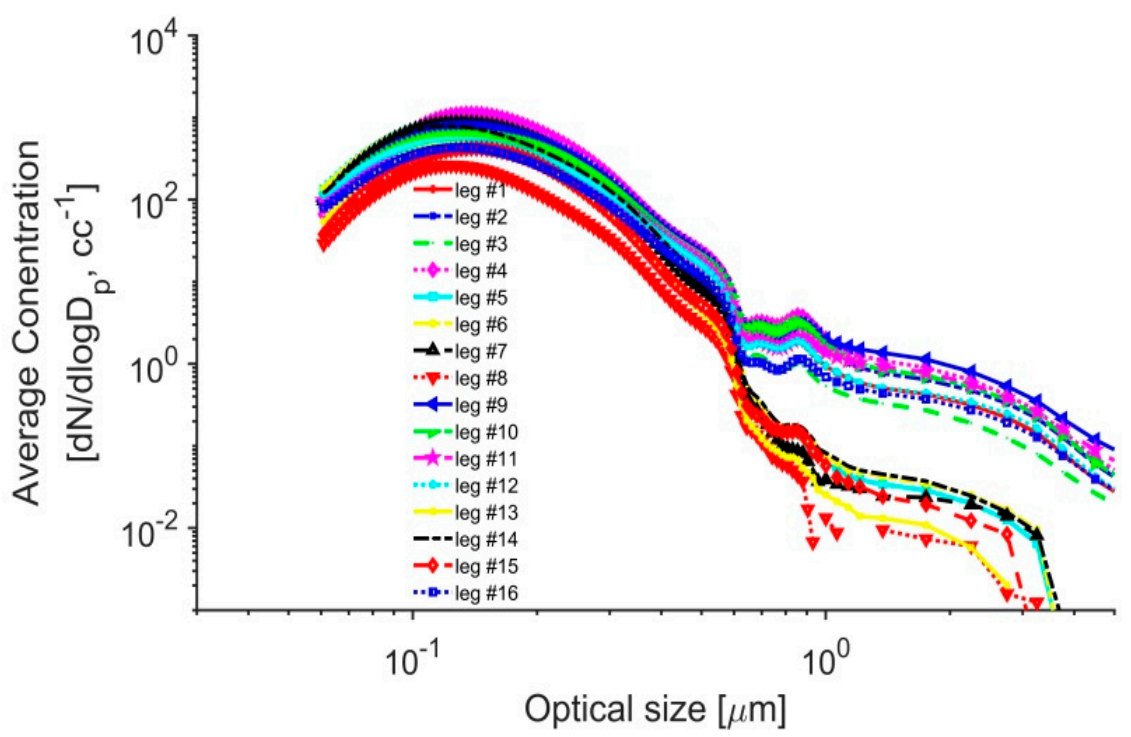

Figure 1. Example of combined size distributions generated for each FL during a given day (25 February 2013). Here and in the following plots, aerosol characteristics represent FL-averaged values. Elevation and time of each FL are shown in Figure 2.

An Aerodyne high resolution time of flight aerosol mass spectrometer (HR-ToF-AMS; Aerodyne Research, Inc., Billerica, MA, USA; abbreviated as AMS hereafter; $[24,25])$ and Droplet Measurement Technology single particle soot photometer (SP2; 0.06-0.6 $\mu \mathrm{m}$ range of mass-equivalent diameter; [26,27]) provided information on the nonrefractory organic and inorganic species mass loading and black carbon (rBC) mass in individual aerosol particles, respectively. This information represents dry conditions. The chemical composition data acquired by AMS defines mostly sub-micron particles due to the size-dependent particle transmission efficiency. For example, the particle 
transmission efficiency is close to 1 for particles with vacuum aerodynamic diameters between 0.06 and $0.6 \mu \mathrm{m}$ and it reduces by half at $1 \mu \mathrm{m}$ [28]. Contributions of sulfate and organic matter (OM) to total mass loading are comparable on 25 February 2013 (Figure 2). Similar contributions of sulfate and $\mathrm{OM}$ are obtained for all winter flights [11]. While the absolute mass loadings of OM, sulfate, nitrate, and $\mathrm{rBC}$ vary for different FLs, the relative fractions of these chemical species remain virtually constant through each individual flight. Note that the dominance of OM was found for all summer flights [10]. Contribution of rBC to total mass loading is substantial for the day of interest (Figure 2) and for all winter flights as well [11].

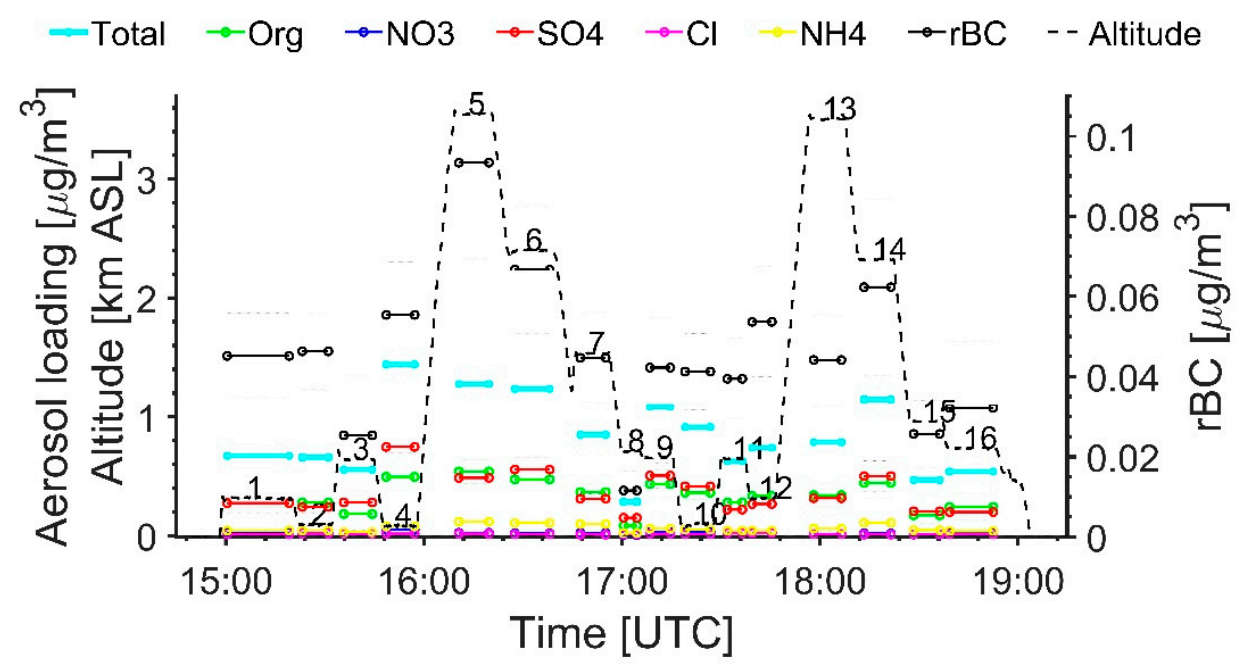

Figure 2. Example of FL-dependent chemical compositions (colored lines) and rBC (thick black lines) mass measured by the AMS and SP2, respectively (25 February 2013). Additionally, altitude (dotted black line) as a function of FL is included. FLs are labeled with numbers 1 through 16 on top of the dashed black altitude line.

To gain further insights into the differences between different FLs, in Figure 3a we present the composition of individual aerosol particles characterized by single particle mass spectrometer, miniSPLAT [29]. miniSPLAT measures in situ and in real-time the size and composition (mixing state) of individual aerosol particles, characterizing both refractory and non-refractory fractions of each particle. During the winter phase of TCAP miniSPLAT characterized composition of nearly 300,000 individual aerosol particles in the size range from $50 \mathrm{~nm}$ to $2 \mu \mathrm{m}$ ( $50 \%$ cut-off at $85 \mathrm{~nm}$ ). These particles were then classified based on their mass spectra into hundreds of classes, which, for simplicity, were subsequently combined into several major aerosol types. Figure 3a shows relative number fractions of particles with different compositions (types), as measured by miniSPLAT along different FLs shown in Figure 2. Aerosol types are depicted by the different colors as indicated in the Figure 3 legend. On this day, the majority ( 70\%; number fraction) of particles on all FLs were composed of sulfate mixed with organics (Org) at different mixing ratios. The number fraction of sulfate-rich particles (red bars, SulfOrg) containing on average $80 \%$ sulfate was $14 \pm 5 \%$, while mixed particles dominated by organics (dark green bars, OrgSulf) containing, on average, $40 \%$ sulfate representing $56 \pm 6 \%$ of all particles characterized on this flight. The weight fractions of organics and sulfate in the mixed particles was determined based on the measurements of their composition-resolved densities, as described in detail in the separate publication [30]. 


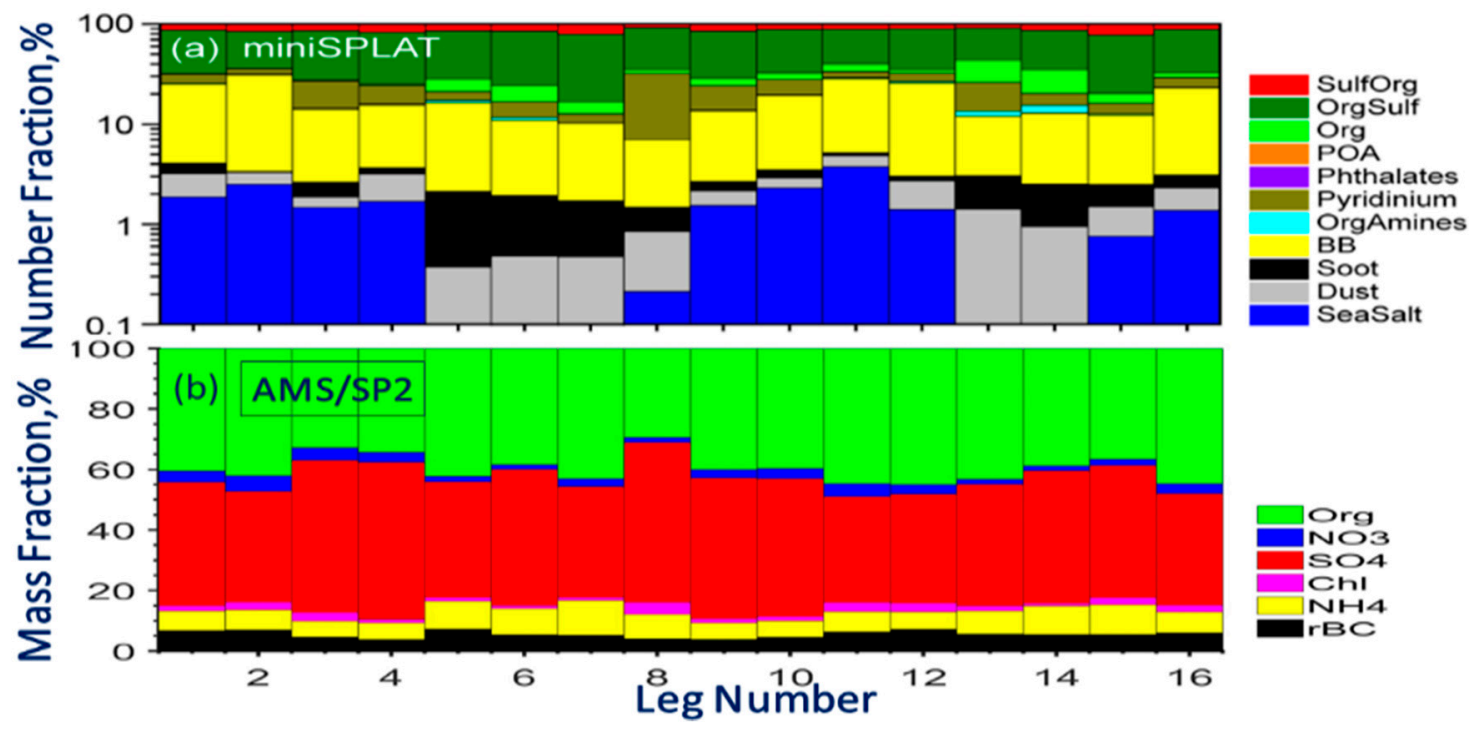

Figure 3. (a) Example of the FL-dependent number fraction of particles with different compositions (note the log scale) characterized by the miniSPLAT during 25 February 2013. Different types of particles are represented by different colors indicated in the legend. The length of each color bar represents the number fraction. The log scale is used to illustrate small $(<3 \%)$ number fraction of sea salt particles characterized on 'shallow' FLs (altitude $<1 \mathrm{~km}$ ). (b) The corresponding mass fraction of different chemical components (note the linear scale) characterized by the AMS and SP2.

Other, less abundant aerosol types—such as biomass burning (BB) aerosol, different types of organic particles, sea salt, dust, and soot particles-were also observed by miniSPLAT during the flight. Some of these particle types exhibit large variations for different FLs. Most noticeable, sea salt particles that are present at low altitudes within boundary layer and are nearly completely "unseen" at higher altitudes.

Figure 3a shows that at low altitudes sea salt particles represent approximately $2 \%$ of all particles characterize by miniSPLAT during this flight. It should be emphasized that the miniSPLAT measures composition of individual particles (both refractory and nonrefractory), while the AMS provides information on bulk composition associated with nonrefractory aerosol. In these regards, the aerosol compositions provided by miniSPLAT and AMS are not directly comparable, as discussed by Berg et al. [10,11]. For example, the AMS-derived aerosol composition (Figure 3b) does not include less abundant aerosol types (dust, soot, and sea salt) characterized by miniSPLAT (Figure 3a). The small levels of chloride measured by the AMS (Figure $3 b$ ) are likely due to ammonium chloride as sodium chloride and other refractory chloride salts are not detected by the AMS. Similar to our summer closer study [19], we use the AMS-derived aerosol chemical composition in our calculations of the winter aerosol properties (Section 3). Since the airborne miniSPLAT data show measurable amount (about $1-3 \%$ by number fraction) of sea salt on some FLs (Figure 3a), we discuss a potential impact of sea salt on the calculated aerosol properties (Section 3), and thus on the level of agreement between the calculated and observed values of the scattering coefficient (Section 4).

A TSI integrating nephelometer (DryNeph; TSI Inc., Model 3563, Shoreview, MN, USA) has measured the total scattering coefficient at three wavelengths $(0.45,0.55,0.7 \mu \mathrm{m})$ at dry $(\mathrm{RH}<40 \%)$ conditions, while a humidification system has measured the light scattering enhancement factor, known as $\mathrm{f}(\mathrm{RH})$ at a single wavelength $(0.525 \mu \mathrm{m})$ at both dry and wet conditions (three RHs have been defined near 45, 65, and 90\%) [31]. Humidification system consists of three integrating nephelometers and humidity conditioners for simultaneous measurement of total scattering coefficient at three different RHs [31]. Similar to Pekour et al. [31], we define $\mathrm{f}(\mathrm{RH})$ as a ratio of wet $(\mathrm{RH}=85 \%)$ and dry $(\mathrm{RH}=40 \%)$ values of the total scattered coefficient at $0.525 \mu \mathrm{m}$ wavelength. We adapt the measured 
$\mathrm{f}(\mathrm{RH})$ to the three wavelengths $(0.45,0.55,0.7 \mu \mathrm{m})$ using an approach described by Shinozuka et al. [32]. Then we apply the spectrally-adapted $\mathrm{f}(\mathrm{RH})$ and the dry total scattering coefficient measured by nephelometer to obtain the total scattering coefficient at ambient conditions $\left(\sigma_{\text {obs }}\right)$ at three wavelengths $(0.45,0.55,0.7 \mu \mathrm{m})$. We compare values of the observed $\left(\sigma_{\text {obs }}\right)$ and model $\left(\sigma_{\bmod }\right)$ total scattering coefficient in Section 4 . These values $\left(\sigma_{\mathrm{obs}}\right.$ and $\left.\sigma_{\mathrm{mod}}\right)$ represent ambient conditions. Figure 4 shows that the FL-dependent variability of $\sigma_{\text {obs }}$ can be large. We assume that uncertainties of the ambient total scattering coefficient for a given FL combine the corresponding variability of $\sigma_{\text {obs }}$ (its standard deviation) and the measurement uncertainties in the dry total scattering. The latter are small $(\sim 10 \%)$ for sub- $\mu \mathrm{m}$ particles and substantial (up to $50 \%$ ) for super- $\mu \mathrm{m}$ particles [33,34]. Note that the isokinetic inlet system used for airborne measurements made inside the G-1 (e.g., TSI nephelometer, AMS, and miniSPLAT) has effective cutoff diameter of $5 \mu \mathrm{m}$. We do not consider in our analysis airborne data collected under very humid conditions $(\mathrm{RH}>80 \%$ ) due to the well-known large uncertainties of the corresponding $\mathrm{f}(\mathrm{RH})$.

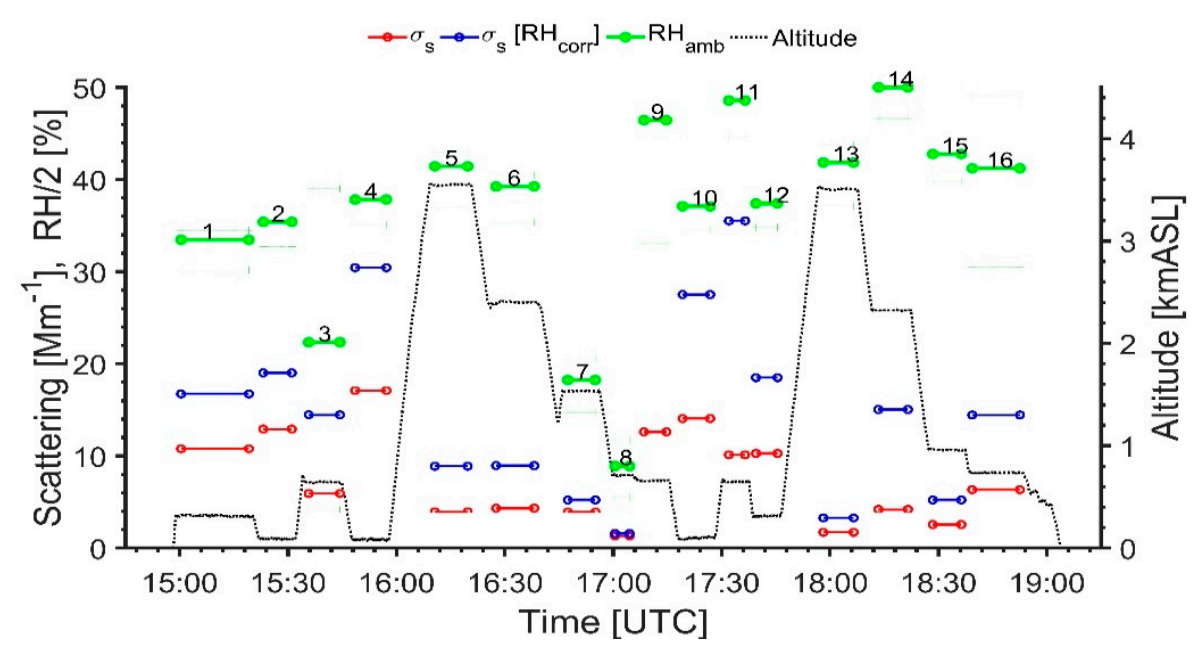

Figure 4. The same as Figure 2, except for the dry scattering coefficient measured by nephelometer (red lines), ambient scattering coefficient obtained with measured $\mathrm{f}(\mathrm{RH})$ (blue lines) at $0.55 \mu \mathrm{m}$ wavelength and ambient RH (green lines). FLs are labeled with numbers 1 through 16 on top of green lines.

To ensure that only good-quality aerosol data are used in this study, we utilize the following three steps. The first two steps are the same as those from our quality assessment previously applied to the summer flights [19]. The first step checks the consistency between the measured size spectra, chemical composition, and total scattering to prevent inclusion of invalid or inconsistent data, while the second step checks for the availability of all data streams required for our analysis. It should be emphasized that clear-sky conditions dominated during the summer flights [10]. In contrast, frequent cloud penetrations by the G-1 were detected during the winter flights. These data within clouds have been excluded from further processing. Sampling through the isokinetic inlet in clouds is subjected to numerous artifacts from cloud droplet shattering in the inlet [35], that can compromise the nephelometer data. The variability test includes the comparison of the FL-averaged value and standard deviation of $\sigma_{\mathrm{obs}}$ for a given FL. We do not consider data when the averaged value is less than the standard deviation. We select 39 FLs with only good-quality data from 87 FLs during 11 winter days. We discuss the seasonal changes of aerosol properties obtained during the winter and summer FLs in the following sections. In our discussion, we use terms 'winter' and 'summer' to define aerosol properties obtained for winter and summer FLs, respectively.

Before we move to the following sections, we make several remarks regarding sea salt aerosol. Sea salt can contribute substantially to the near-surface aerosol microphysical and optical properties under windy conditions [36]. Data related to sea salt are available from the complementary 
ground-based TCAP measurements [11]. Mass loading of $\mathrm{NaCl}$ aerosol was measured by the ARM Particle-into-Liquid Sampler (PILS) instrument [37]. Note that $\mathrm{NaCl}$ makes up the major fraction of sea salt overall [38]. The ground-based in-situ measurements demonstrate that the near-surface mass loadings of both sodium $(\mathrm{Na})$ and chloride $(\mathrm{Cl})$ during winter can substantially exceed (by as much as an order of magnitude) their summer mass loadings [11]. Similarly, airborne measurements by miniSPLAT indicate that during winter TCAP sea salt particles accounted for $1.0 \pm 1.6 \%$ as compared to $0.16 \pm 0.35 \%$ during summer and the vast majority of these particles were observed at shallow FLs, as illustrated in Figure 3a for one of the flights. Moreover, the ground-based meteorological measurements of thermodynamic structure of atmosphere demonstrate that about 1-km convective boundary layer is typical for winter, associated with relatively cold continental air moving over relatively warm Atlantic Ocean [11]. Thus, these combined in situ and meteorological measurements suggest that the relative contribution of the sea salt to the total mass loading could be substantial for several winter FLs, particularly those flown at low altitude. We discuss the potential impact of sea salt on our results in the following sections.

\section{Model and Adjustments}

Important aerosol parameters pertinent to the optical closure results (Section 4) are considered in this section. These parameters characterize the model components of the framework for an optical closure experiment introduced by Kassianov et al. [19] and include the hygroscopic growth factor (Section 3.1), ambient complex RI (Section 3.2), RI-corrected size spectra obtained from the OPC measurements (Section 3.3) and model total scattering coefficient at ambient conditions (Section 3.4). The major assumptions required for estimating these parameters are also given. The reader is referred to our previous study [19] for details of the framework, models, and assumptions.

\subsection{Hygroscopic Growth Factor}

Atmospheric aerosol is a mixture of compounds with different hygroscopicity. Thus, the relative fractions of these components control the response of aerosol particles to the ambient humidity. This response is commonly described by the hygroscopic growth factor of the mixture $\left(\mathrm{HGF}_{\text {mix }}\right)$ [39] and its estimation typically involves the volume-weighted average relationship together with the volume fractions and growth factors of individual components. Similar to our previous study [19], we use this relationship to obtain the required volume fractions using the mass fractions measured by the AMS and SP2 airborne instruments (Section 2) and the corresponding densities (Table 1).

Table 1. Assumed size-independent density, real and imaginary parts of complex refractive index (RI) at $0.55 \mu \mathrm{m}$ wavelength, and hygroscopic growth factor (HGF) values used in this study. Values are taken from [39-41]. Also, this table includes values of these parameters for sea salt (or sodium chloride; $\mathrm{NaCl}$ ) from Xie et al. [42].

\begin{tabular}{ccccccccc}
\hline Parameters & $\mathrm{OM}$ & $\mathrm{SO}_{4}$ & $\mathrm{NO}_{3}$ & $\mathrm{Cl}$ & $\mathrm{NH}_{4}$ & $\mathbf{r B C}$ & Water & $\mathbf{N a C l}$ \\
\hline Density $\left(\mathrm{g} / \mathrm{cm}^{3}\right)$ & 1.4 & 1.8 & 1.8 & 1.53 & 1.8 & 1.8 & 1.0 & 2.2 \\
RI (real) & 1.45 & 1.52 & 1.5 & 1.64 & 1.5 & 1.85 & 1.33 & 1.55 \\
RI (imag) & 0.0 & 0 & 0 & 0 & 0 & 0.71 & 0 & 0 \\
HGF $(\mathrm{RH}=80 \%)$ & 1.07 & 1.50 & 1.50 & 1.9 & 1.50 & 1.0 & - & 1.9 \\
\hline
\end{tabular}

It should be emphasized that the measured mass fractions correspond to sub- $\mu \mathrm{m}$ particles. However, we apply the volume-weighted average relationship for both sub- and super- $\mu \mathrm{m}$ particles assuming that these fractions are size-independent. We also assume that the RH-dependence of $\mathrm{HGF}_{\text {mix }}$ is approximated by the empirically based power law [43,44]. The $\mathrm{HGF}_{\text {mix }}$ increases with $\mathrm{RH}$ and its growth rate is governed by the relative fractions of hydrophobic and hydrophilic components. More hydroscopic sulfate ( $\mathrm{HGF}=1.5$ at $\mathrm{RH}=80 \%$ ) together with barely hydroscopic OM ( $\mathrm{HGF}=1.07$ at $\mathrm{RH}=80 \%$ ) dominate the total mass loading during winter FLs [11], while OM is the 


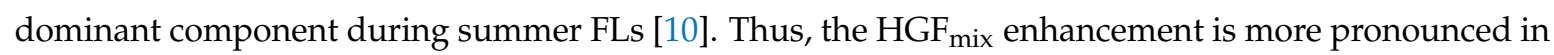
winter $\left(\mathrm{HGF}_{\text {mix }}\right.$ range is about from 1 to 1.3 ; Figure 5$)$ compared to that in summer ( $\mathrm{HGF}_{\text {mix }}$ range is about from 1 to 1.2; Figure 5; from [19]). Note that sodium chloride (similar to sulfate) has large value of HGF in comparison with that for OM (Table 1). Thus, potential inclusion of $\mathrm{NaCl}$ in the $\mathrm{HGF}_{\text {mix }}$ calculations would increase the computed HGF $_{\text {mix }}$ enhancement.
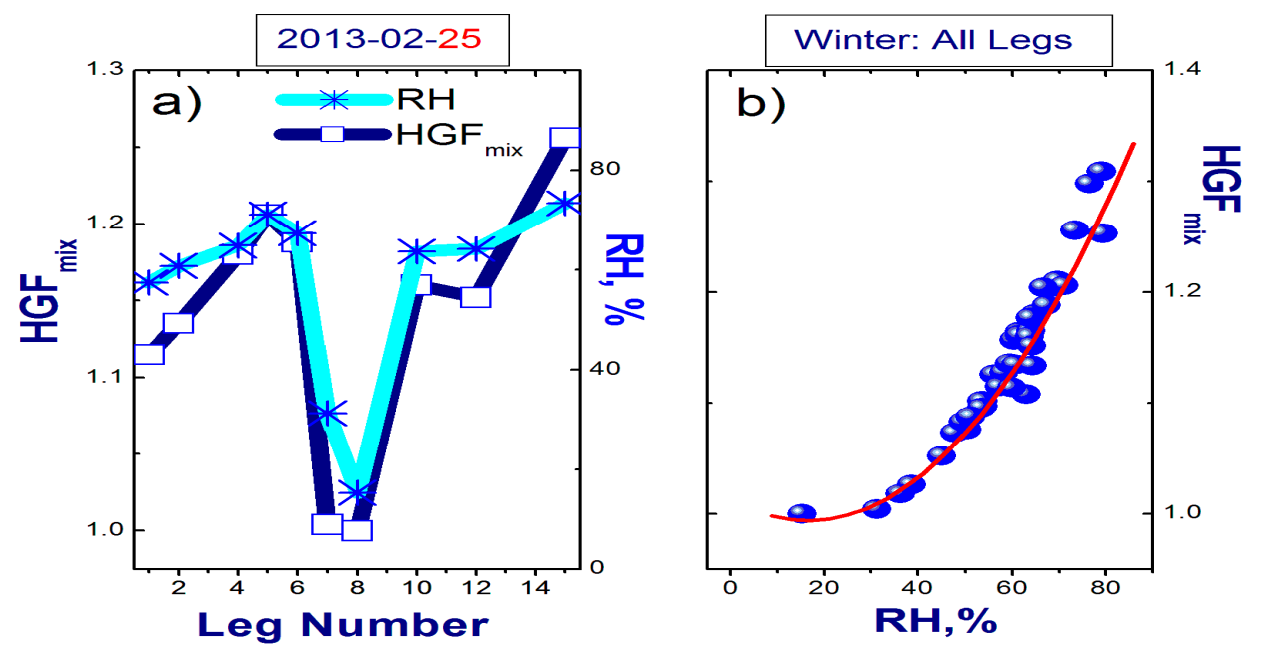

Figure 5. Example of ambient RH and RH-dependent $\mathrm{HGF}_{\text {mix }}$ calculated for each FL on 25 February 2013 (a); scatterplot of RH-dependent HGF mix (blue dots) for all TCAP FLs used in this study with polynomial fit (red line) (b).

\subsection{Dry and Wet Refractive Indices}

We apply the estimated volume fractions of aerosol composition and HGF mix (Section 3.1) to calculate the size-independent real ( $\left.\mathrm{n}_{\mathrm{wet}}\right)$ and imaginary $\left(\mathrm{k}_{\mathrm{wet}}\right)$ parts of the complex RI at ambient conditions. These aerosol parameters $\left(\mathrm{n}_{\text {wet }}\right.$ and $\left.\mathrm{k}_{\mathrm{wet}}\right)$ represent a mixture of the measured chemical components (Table 1 ) and absorbed water. We start with calculations of their dry values $\left(n_{d r y}\right.$ and $\left.k_{d r y}\right)$ using a volume weighting method [45]. In our calculations we use the real and imaginary parts of the complex RI for each component (Table 1) and the estimated volume fractions. The volume fractions are calculated from the mass fractions (Figure $3 b$ ) and densities (Table 1). We also assume that particles with different sizes have the same complex RI. We continue with calculations of the ambient values ( $\mathrm{n}_{\text {wet }}$ and $\mathrm{k}_{\mathrm{wet}}$ ) using the estimated values of $\mathrm{HGF}_{\text {mix }}$ for a given $\mathrm{RH}$ (Section 3.1) and a well-known empirical model for converting the dry complex RIs into their ambient counterparts [44,46]. Figure 6 shows the dry and ambient values of the complex RI estimated for winter FLs.

The relative contributions of sulfate and $\mathrm{rBC}$ to the total mass have the substantial seasonal changes (Section 2). These changes are mainly responsible for the observed differences between the dry values of the complex RI (Figure 6). For example, winter dry values $(1.50 \pm 0.007)$ of the real RI (Figure 6c) are larger than their summer values (1.46 \pm 0.005$)$ (Figure 6c; [19]) due to the larger contribution of sulfate to total mass in winter (Section 2). Similarly, winter values of the imaginary RI (Figure 6d) exceed their summer values (Figure 6d; [19]) considerably (about three times on average) due to the larger fraction of $\mathrm{rBC}$ in the total mass in winter (Section 2). Thus, winter particles in comparison with summer particles have an enhanced ability to absorb sunlight. As a result, the calculated winter single-scattering albedo $(0.90 \pm 0.05)$ is smaller than its summer counterpart $(0.93 \pm 0.03)$ for the TCAP dataset considered here. Results from performed $t$-test for two means (unknown population standard deviations) suggest that there is enough evidence to claim that the winter and summer values of both the real RI and single-scattering albedo are different at the 0.05 significance level. It should be mentioned that a potential inclusion of sea salt aerosol into calculations of the complex RI for a mixture would lead to increases of $n_{\text {dry }}$ and reductions of $k_{d r y}$. 
Particles have a stronger ability to absorb water during winter in comparison with summer (Section 3.1). Thus, differences between wet and dry values (both $n_{w e t}$ versus $n_{d r y}$ and $k_{w e t}$ versus $k_{d r y}$ ) are greater during winter (Figure 6) as compared with those in summer (Figure 6; [19]).

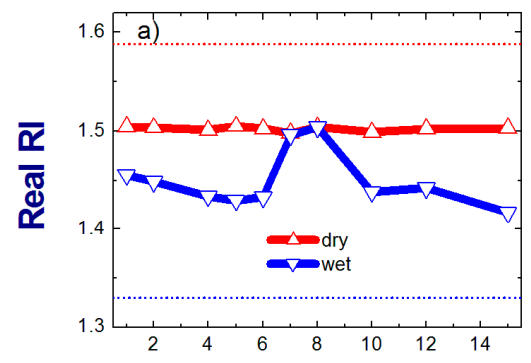

Leg Number

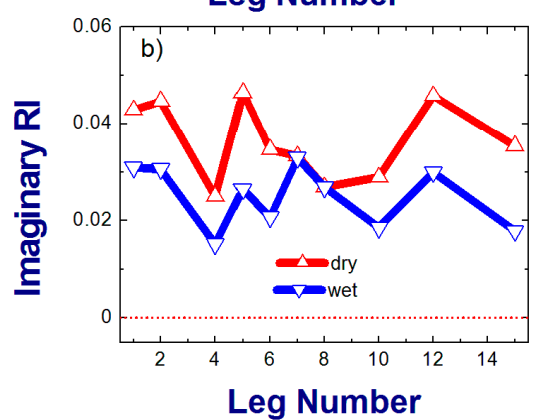

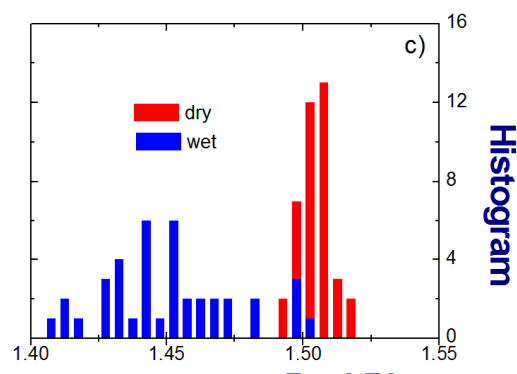

Real RI

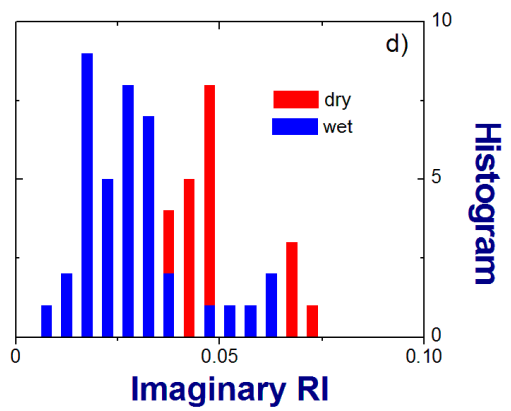

Figure 6. Example of RH-dependent dry and ambient values of the real and imaginary parts of the complex RI calculated for each FL on 25 February 2013 (a,b); the corresponding histograms obtained for all winter TCAP FLs $(\mathbf{c}, \mathbf{d})$. The real $\left(\mathrm{n}_{\mathrm{OPC}}=1.588\right)$ and imaginary $\left(\mathrm{k}_{\mathrm{OPC}}=0\right)$ parts of the complex RI set for OPC calibration are shown in (a) (magenta) and (b) (magenta), respectively. The real RI of water $\left(n_{\text {water }}=1.33\right)$ is also shown ( $a$, cyan). The imaginary RI of water $\left(k_{\text {water }}=0\right)$ is equal to the imaginary RI used for OPC calibration $\left(\mathrm{k}_{\mathrm{OPC}}=0\right)$.

\subsection{Size Distribution}

We apply the size spectra derived from the OPC measurements (Section 2), the estimated HGF mix (Section 3.1) and ambient complex RI (Section 3.2) to obtain size distributions at ambient conditions with and without RI-based correction (Figure 7). This correction takes into account for the difference between the complex RI estimated from the measured chemical composition (Section 3.2) and the complex RI used for the OPC calibration $\left(\mathrm{n}_{\mathrm{OPC}}=1.588\right.$ and $\left.\mathrm{k}_{\mathrm{OPC}}=0\right)$, while the RH correction incorporates the particle growth due to the water uptake [19]. We start with estimation of the RI-based correction. This estimation involves the size-dependent scaling factor obtained from the theoretical response calculations for a given complex RI. Application of the RI-based correction modifies the original OPC-derived size spectra in two ways by (1) changing bin boundaries (horizontal shifting) and (2) scaling of the normalized number concentration (vertical shifting). We continue with estimation of the RH-based correction. This estimation involves the size-independent $\mathrm{HGF}_{\text {mix }}$ calculated from the chemical composition measurements (Section 3.2). Application of the RI-based correction modifies the original OPC-derived size spectra by changing bin boundaries (horizontal shifting) only.

The hygroscopicity of particles has distinct seasonal changes (Section 3.1). These changes determine, in turn, the observed seasonal differences between the dry and ambient size spectra. To illustrate, let us consider the corresponding spectra obtained without the RI-based correction for a winter FL where the ambient RH was near 80\% (Figure 7a,b). The wet size distribution is shifted substantially along the horizontal axis (Figure $7 \mathrm{a}, \mathrm{b}$ ) due to the considerable hygroscopicity of winter particles in comparison with the dry size distribution. Such horizontal shifting is less pronounced for a summer FL with comparable RH (Figure 7a,b; [19]) due to the smaller hygroscopicity of summer 
particles. Recall, that the ability of particles to scatter and absorb sunlight is governed by their real and imaginary parts of complex RI, respectively. The latter have the distinct seasonal changes as well (Section 3.1) and these changes are responsible for differences between the size spectra obtained with $\left(\mathrm{dN} / \mathrm{d} \log \mathrm{D}_{\text {wet,adj }}\right)$ and without $\left(\mathrm{dN} / \mathrm{d} \log \mathrm{D}_{\text {wet }}\right)$ the RI-based correction for winter (Figure $\left.7 \mathrm{a}, \mathrm{b}\right)$ and summer (Figure 7a,b; [19]).
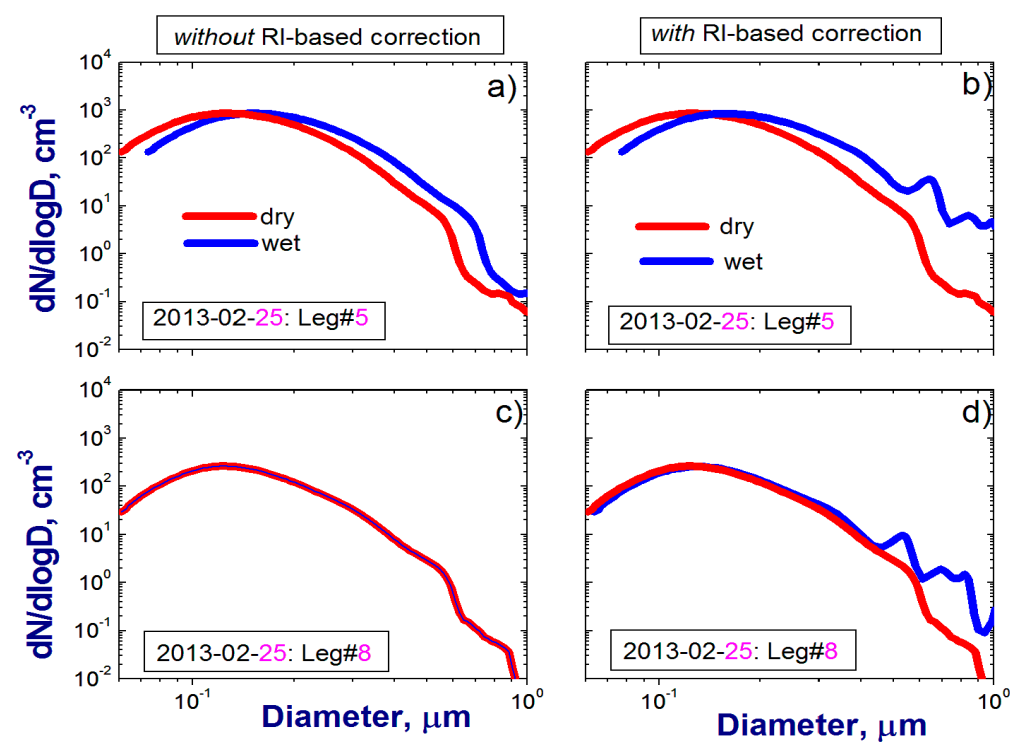

Figure 7. Example of size distributions obtained for two FLs on 25 February 2013 with large (a,b) and small (c,d) values of ambient RH, respectively. Measured dry size distributions (red) are converted into their wet counterparts (blue) without $(\mathbf{a}, \mathbf{c})$ and with $(\mathbf{b}, \mathbf{d})$ the size-dependent scaling factor.

\subsection{Scattering Coefficient Calculations}

We apply the estimated complex RI (Section 3.2) and the obtained ambient size distributions (Section 3.3) to calculate the ambient total scattering coefficient $\left(\sigma_{\bmod }\right)$. In our Mie calculations, we assume that particles are homogeneous spheres and effective values of the complex RI are size-independent. We perform these calculations using the size distributions obtained with $\left(\mathrm{dN} / \mathrm{d} \log \mathrm{D}_{\text {wet,adj }}\right)$ and without $\left(\mathrm{dN} / \mathrm{d} \log \mathrm{D}_{\text {wet }}\right)$ the RI-based correction. The corresponding values of the model ambient total scattering coefficient $\left(\sigma_{\text {mod,adj }}\right.$ and $\left.\sigma_{\text {mod,org }}\right)$ are output of our calculations. Since the transmission efficiency for the sampling system with airborne TSI integrating nephelometer falls significantly (up to $90 \%$ ) at $5 \mu \mathrm{m}$ diameter (Section 2), we calculate the total scattering coefficients using a $5-\mu \mathrm{m}$ cut-off. Thus, the model total scattering coefficients represents both sub- and super- $\mu \mathrm{m}$ particles. We discuss the relative contribution of super- $\mu \mathrm{m}$ particles to the model total scattering coefficient in Section 4. Although the complex RI is obtained at single wavelength $(0.55 \mu \mathrm{m})$, we calculate the total scattering coefficient at three wavelengths $(0.45,0.55,0.7 \mu \mathrm{m})$ assuming that the complex RI does not change within the spectral range of interest $(0.45-0.7 \mu \mathrm{m})$. Ambiguities of the required inputs (ambient size distribution and complex RI) and model assumptions (homogeneous internal mixture) contribute to the uncertainties for the calculated scattering coefficient. Similar to the previous studies [19,47], we assume that $20 \%$ uncertainties associated with the required inputs (ambient size spectra and complex RI) and model assumptions (homogeneous internal mixture) are representative for the calculated ambient total scattering coefficients at least as a lower limit.

\section{Results and Discussion}

This section further illustrates application of the framework introduced by Kassianov et al. [19] and its extension to the winter conditions, which are characterized by more frequent clouds and increased fraction of super- $\mu \mathrm{m}$ particles. We can now assess the consistency and reasonableness of the 
integrated data and appropriateness of assumptions considered in the previous sections. For example, the assumption of the size-independent complex RI is critical (Section 3), and its importance should not be overlooked, especially for FLs where contribution of the super- $\mu \mathrm{m}$ particles to aerosol microphysical and optical properties is substantial. For our assessment, we answer the question: What level of agreement between the measured and calculated total scattering coefficients can be achieved for challenging wintertime conditions?

The comparison of the observed $\left(\sigma_{\mathrm{obs}}\right)$ and model $\left(\sigma_{\mathrm{mod}}\right)$ scattering coefficients for a given day of interest (Figure 8) is a good start for the subsequent discussion of results obtained for all winter FLs (Figure 9, Table 2). The general message of our results (Figures 8 and 9; Table 2) is that application of the measured chemical composition substantially improves agreement between the measured and calculated values of total scattering coefficient.

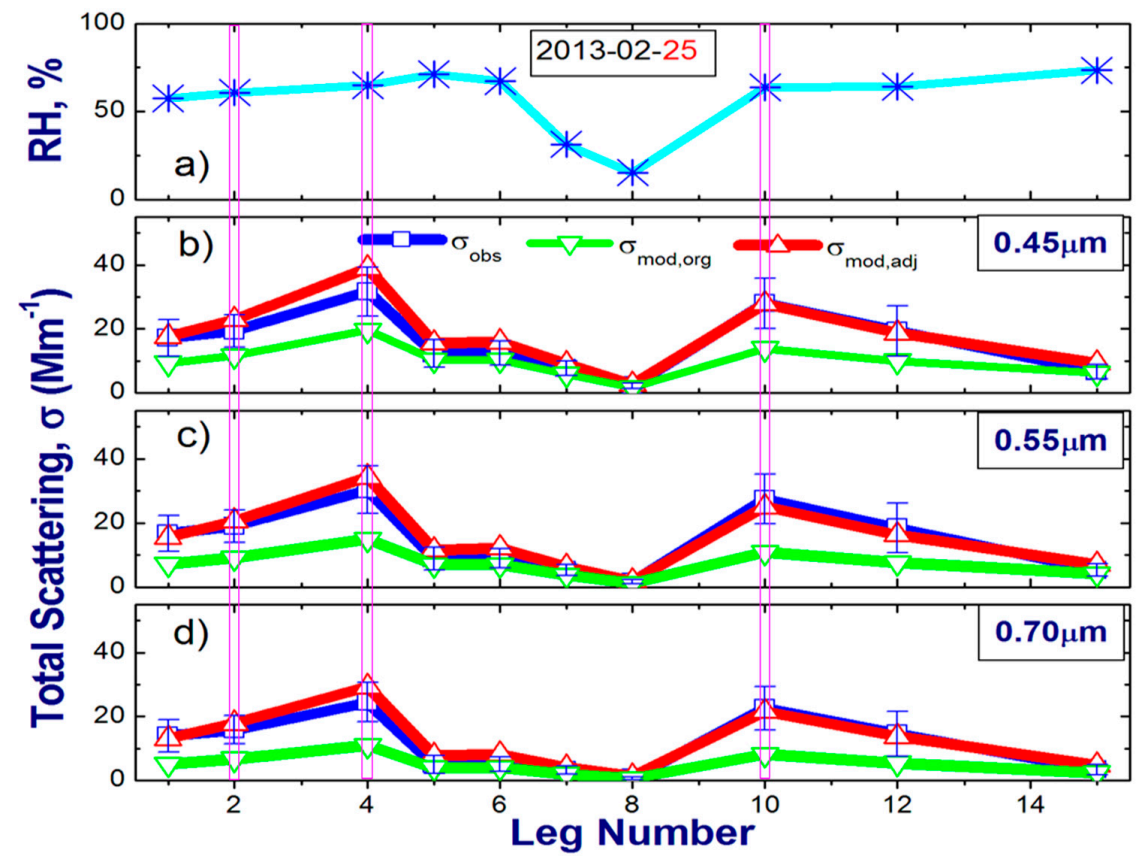

Figure 8. Ambient RH (a) and spectral values (b-d) of the total scattering coefficient measured (blue) and calculated for the original (green) and RI-based adjusted (red) size distributions for FLs on 25 February 2013 at three wavelengths: (b) 0.45 , (c) 0.55 , and (d) $0.70 \mu \mathrm{m}$. Error bars represent uncertainties of measured scattering coefficients. Vertical columns (magenta) identify shallow FLs with low $(<0.1 \mathrm{~km})$ altitude (Figure 2$)$.

Our comparison includes the model scattering coefficients calculated with $\left(\sigma_{\text {mod,adj }}\right)$ and without $\left(\sigma_{\text {mod,org }}\right)$ the RI-based correction (Section 3$)$. The range of the observed scattering coefficient $\sigma_{\text {obs }}$ as a function of FL is wider in winter (Figure 8) in comparison with the analogous range in summer (Figure 8; [19]). The corresponding winter and summer ranges for the days of interest are about $2-30 \mathrm{Mm}^{-1}$ and $6-11 \mathrm{Mm}^{-1}$ at $0.55 \mu \mathrm{m}$ wavelength, respectively. Note that small values of $\sigma_{\text {obs }}$ are found on FLs with the high altitude (above $3 \mathrm{~km}$ ). The seasonal differences of aerosol properties together with the related meteorological content are discussed in detail by Berg et al. [11]. The observed and RI-adjusted model scattering coefficients coincide reasonably well (mostly within observational uncertainty) at $0.55 \mu \mathrm{m}$ wavelength (Figure $8 \mathrm{c}$ ) despite their strong temporal variability. The same is true for other wavelengths (Figure $8 b, d$ ). Thus, our assumption regarding the spectral dependence of the complex RI (Section 3.4) seems to be reasonable for the TCAP dataset considered here. In contrast to $\sigma_{\text {mod,adj }}, \sigma_{\text {mod,org }}$ substantially underestimates (by up to $60 \%$ ) the observed total scattering coefficient (Figure 8c). 
It should be emphasized that reasonable agreement (within observational uncertainties) between $\sigma_{\text {obs }}$ and $\sigma_{\text {mod,adj }}$ is obtained even for FLs where the relative contribution of the super- $\mu \mathrm{m}$ particles to the model total scattering is substantial (Figure 8c). To be more specific, let us consider three FLs (number 2, 4, and 10) where the measured size spectra show a noticeable fraction of super- $\mu \mathrm{m}$ particles (Figure 1). These three FLs were very low $(<0.1 \mathrm{~km})$ (Figure 2), and thus represent the near-surface aerosol sampling over ocean. The estimated contribution of super- $\mu \mathrm{m}$ particles to $\sigma_{\text {mod,adj }}$ is considerable (up to $45 \%$ ) for these "shallow" FLs, while it is more than two times less ( 19\%) for all winter FLs (Appendix A). The obtained winter contribution (19\%) exceeds substantially (about three times) the corresponding summer (7\%) contribution (Appendix A; [19]). The outlined seasonal changes of this contribution (winter versus summer) are consistent with related finding from the previous TCAP-related study [8].

The obtained reasonable agreement between $\sigma_{\mathrm{obs}}$ and $\sigma_{\text {mod,adj }}$ for these three 'shallow' FLs (altitude $<0.1 \mathrm{~km}$ ) seems unexpected mainly because we use sub- $\mu \mathrm{m}$ values of the complex RI to calculate the RI-adjusted scattering coefficient, which defines both sub- and super- $\mu \mathrm{m}$ particles (Section 3). In other words, we use the assumption of size-independent complex RI in our calculations. This assumption would not favor, in general, the comparison between the observed and model scattering coefficients especially for cases where sub- and super- $\mu \mathrm{m}$ particles have distinctly different values of the complex RI due to different chemical composition. However, the potential consequences are minimized in our study as the values of the complex RI are quite similar for sulfate and sea salt (Table 1). Note that sea salt contribution to the number fraction is noticeable (up to 3\%) for these FLs (Figure 3). Thus, the obtained reasonable agreement suggests that the noticeable contribution of large sea salt particles to the near-surface (altitude $<0.1 \mathrm{~km}$ ) aerosol properties does not substantially modify the estimated super- $\mu \mathrm{m}$ values of the complex RI, and thus the RI-adjusted values of the scattering coefficient calculated for both sub- and super- $\mu \mathrm{m}$ particles.

Let us compare the observed and model values of the total scattering coefficients acquired for all winter FLs. We describe the relationship between them graphically by scatterplots (Figure 9), as well as numerically (Table 2).
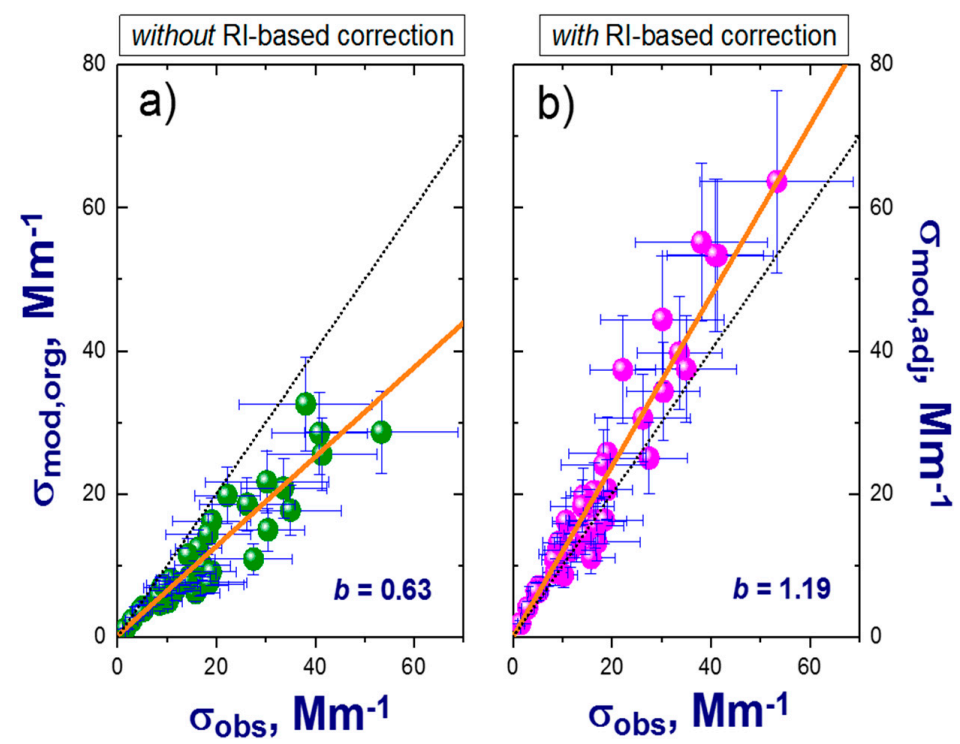

Figure 9. Comparison of the ambient total scattering coefficient observed $\left(\sigma_{\mathrm{obs}}\right)$ with ambient total scattering calculated $\left(\sigma_{\bmod }\right)$ for the original (a) and RI-based adjusted (b) size distributions at 0.55 $\mu \mathrm{m}$ wavelength for all TCAP FLs. Here $b$ is the slope of the linear regression fits to the data (straight orange lines). Error bars represent uncertainties of measured (Section 2) and calculated (Section 3.4) scattering coefficients. 
To begin, consider the relationship between $\sigma_{\text {obs }}$ and $\sigma_{\text {mod,org }}$ (Figure 9a): the points diverge from the 1:1 line, and thus the slope (0.63) is far from unity. There are three points with large values of observed scattering coefficient $\left(\sigma_{\mathrm{obs}}>40 \mathrm{Mm}^{-1}\right.$, Figure $\left.9 \mathrm{~b}\right)$. These points represent conditions with either large values of $\mathrm{RH}(>60 \%)$ or substantial fraction of super- $\mu \mathrm{m}$ particles $(>25 \%)$. The scatterplots include the best linear fits estimated by the bivariate weighted method [48], while Table 2 contains parameters of these fits (both intercepts and slopes). Note that this slope (0.63) is about $10 \%$ smaller the corresponding summer slope (Figure 9a; [19]). Therefore, ignoring of the RI-based correction results in even larger underestimation of the model scattering coefficient ( $\sigma_{\text {mod,org }}$ versus $\sigma_{\text {obs }}$ ) during winter compared to summer. Such underestimation can be explained (at least in part) by stronger ability of winter particles to absorb sunlight (Section 3.2). Recall, that the RI-based correction takes into account the ability of particles to absorb sunlight and this correction is ignored for $\sigma_{\text {mod,org }}$ calculations. The outlined underestimation and its seasonal changes are responsible for the corresponding differences between root mean squared errors (RMSE) —its winter value (8.77; Table 2) exceeds the summer value (6.99; Table 2; [19]) noticeably $(\sim 20 \%)$. It is quite interesting to note that the difference between mean values of $\sigma_{\text {obs }}$ and $\sigma_{\text {mod,org }}$ is about $40 \%$ (Table 2) and this difference depends weakly on season (winter versus summer).

To continue, consider the relationship between $\sigma_{\text {obs }}$ and $\sigma_{\text {mod,adj }}$ (Figure $9 b$ ): the points cluster more tightly around the 1:1 line, and the slope (1.19) is closer to unity. The difference between mean values of $\sigma_{\text {obs }}$ and $\sigma_{\text {mod,adj }}$ is about $20 \%$ (Table 2). This difference, in combination with the obtained values of slope and RMSE (Table 2), clearly show that application of the RI-based correction substantially improves the agreement between the observed and model scattering coefficients (Figure 9; Table 2). Since application of the RI-based correction requires several assumptions outlined in the previous section, a reasonable level of agreement (about 20\%) between the mean values of $\sigma_{\text {obs }}$ and $\sigma_{\text {mod,adj }}$ also suggests that a moderate departure from 'favorable' conditions specified by these assumptions would not substantially hinder the overall relationship between observed and RI-adjusted scattering coefficients.

Table 2. Mean and standard deviation (StDv) of the observed $\left(\sigma_{\mathrm{obs}}\right)$ and calculated ( $\sigma_{\text {mod,org }}$ and $\left.\sigma_{\text {mod,adj }}\right)$ scattering coefficients obtained for all TCAP FLs at three wavelengths. The corresponding intercept (a), slope (b), their standard errors (in parenthesis) and Root Mean Squared Error (RMSE) also are included. The RMSE is defined as the root mean squared difference between the observed and the calculated scattering coefficients.

\begin{tabular}{|c|c|c|c|c|c|}
\hline Scattering Coefficients & Mean & StDv & RMSE & $a$ & $b$ \\
\hline \multicolumn{6}{|c|}{$0.45 \mu \mathrm{m}$} \\
\hline$\sigma_{\text {obs }}$ & 21.80 & 14.35 & - & - & - \\
\hline$\sigma_{\text {mod,org }}$ & 15.96 & 11.04 & 7.51 & $0.30(0.60)$ & $0.73(0.06)$ \\
\hline$\sigma_{\text {mod,adj }}$ & 26.73 & 18.86 & 7.56 & $\mathbf{0 . 1 1}(0.99)$ & $1.22(0.10)$ \\
\hline \multicolumn{6}{|c|}{$0.55 \mu \mathrm{m}$} \\
\hline$\sigma_{\text {obs }}$ & 18.18 & 12.11 & - & - & - \\
\hline$\sigma_{\text {mod,org }}$ & 11.39 & 7.94 & 8.77 & $0.21(0.42)$ & $\mathbf{0 . 6 3}(0.05)$ \\
\hline$\sigma_{\text {mod,adj }}$ & 21.68 & 15.72 & 6.17 & $0.08(0.79)$ & $1.19(0.10)$ \\
\hline \multicolumn{6}{|c|}{$0.70 \mu \mathrm{m}$} \\
\hline$\sigma_{\text {obs }}$ & 12.89 & 9.17 & - & - & - \\
\hline$\sigma_{\text {mod,org }}$ & 7.34 & 5.28 & 7.43 & $0.23(0.26)$ & $0.56(0.05)$ \\
\hline$\sigma_{\text {mod,adj }}$ & 16.43 & 12.77 & 6.07 & $0.25(0.57)$ & $1.25(0.11)$ \\
\hline
\end{tabular}

\section{Summary}

We examine the performance of the approach introduce by Kassianov et al. [19] to assess the consistency and reasonableness of airborne data in the context of closure study of the ambient total aerosol scattering coefficient. For our extended assessment, we use an integrated dataset collected by the DOE G-1 aircraft during the winter of 2013 as part of the Two-Column Aerosol Project 
(TCAP) campaign [11]. This dataset includes: (1) size distributions measured by three optical particle counters (OPCs): an ultra-high sensitivity aerosol spectrometer (UHSAS; particle size range $0.06-1 \mu \mathrm{m}$ ), a passive cavity aerosol spectrometer (PCASP; particle size range $0.1-3 \mu \mathrm{m}$ ), and a cloud and aerosol spectrometer (CAS; particle size range $0.6-10 \mu \mathrm{m}$ ) mounted on the G-1; (2) chemical composition data measured by three instruments: an aerosol mass spectrometer (AMS; particle size range 0.06-0.6 $\mu \mathrm{m}$ ) a single particle soot photometer (SP2; particle size range $0.06-0.6 \mu \mathrm{m}$ ), and a single particle mass spectrometer (miniSPLAT; particle size range $0.05-2 \mu \mathrm{m}$ ); and (3) the dry total scattering coefficient measured by TSI integrating nephelometer (particle size range $0.06-5 \mu \mathrm{m}$ ) at three wavelengths $(0.45,0.55,0.7 \mu \mathrm{m})$ and $\mathrm{f}(\mathrm{RH})$ measured with a humidification system at three values (near 45,65 , and $90 \%)$ of relative humidity $(\mathrm{RH})$ at a single wavelength $(0.525 \mu \mathrm{m})$. The measured size spectra and chemical composition in combination with the measured $\mathrm{RH}$ are used to estimate the ambient complex refractive index (RI) and the RI-based correction for the OPC-derived size spectra, and thus to calculate the model total scattering coefficient at ambient conditions.

We demonstrate that a reasonable level of agreement (about $20 \%$ at $0.55 \mu \mathrm{m}$ wavelength on average) between the observed and calculated values of the scattering coefficient can be achieved at ambient conditions with a wide range of RH (5-80\%) if the RI-based correction is applied for the OPC-derived size spectra. The corresponding root mean square error (RMSE), which is defined as the root mean squared difference between the observed and the calculated values, is reasonable (about $6 \mathrm{Mm}^{-1}$ ) as well. This level of agreement suggests that a moderate departure from the conditions specified by several assumptions in our approach do not significantly impact our results. For example, we use several assumptions in our Mie calculations of the total scattering coefficient, such as assumptions of the internal mixture and size-independent complex RI (or chemical composition). Note that the internal mixing assumption can lead to uncertainties in the calculated aerosol optical properties and miniSPLAT data could be used to include variable size-dependent mixing state in these calculations [49-51]. The assumption of the size-independent complex RI would be likely practical even for potential events where the aerosol properties are influenced noticeably by sea salt because of two main reasons: (1) sulfate (sub- $\mu \mathrm{m}$ particles) and sea salt (super- $\mu \mathrm{m}$ particles) have comparable values of the complex RI, and (2) sulfate contributes considerably to the total aerosol mass in winter. We also demonstrate that the calculated ambient scattering coefficient can substantially underestimate (about $40 \%$ at $0.55 \mu \mathrm{m}$ wavelengths on average) the observed one if the RI-based correction is ignored for cases in which the complex RI estimated from the measured chemical composition and that used for the OPC calibration are very different. The corresponding RMSE is substantial (about $9 \mathrm{Mm}^{-1}$ ) as well. The obtained substantial underestimation $(\sim 40 \%)$ of the calculated scattering coefficient provides additional evidence of the importance of the RI-based correction.

We illustrate that there are differences between the airborne in situ data collected during summer [19] and winter (this study). The winter observations are characterized by more frequent clouds, which increase the variability of the observed scattering coefficient. To ensure that only high-quality aerosol data are preserved, we identify the cloud penetrations and remove the corresponding cloud-contaminated data from our analysis. We also demonstrate that the winter dataset represent more hygroscopic particles and particles with an enhanced ability to absorb sunlight. As a result, the single-scattering albedo is smaller in winter $(0.90 \pm 0.05)$ in comparison to summer $(0.93 \pm 0.03)$. Moreover, the winter dataset has a larger fraction of super- $\mu \mathrm{m}$ particles in the OPC-derived size distributions and thus in the calculated total scattering (on average 19\% for winter versus $7 \%$ for summer). The detailed review of the seasonal changes of the microphysical, chemical, and optical aerosol properties and comparison of the TCAP results with those from previous studies is given by Berg et al. [11]. The TCAP results discussed here represent mostly background coastal conditions. Additional studies are needed to illustrate performance of our approach under polluted conditions typically observed over large urban areas.

The airborne measurements of physical and chemical properties of aerosol at different spatial and temporal scales are imperative additions for many climate-relevant studies and provide a critical data 
set for evaluating the model performance [52] and inter-comparison of aerosol optical properties obtained from in situ measurements and remote sensing [53]. In view of these considerations, assessment of the consistency and reasonableness of airborne data plays a critical role and our introduced approach offers the opportunity for such assessment. It is expected that application of this approach together with complementary measurements of aerosol and cloud properties from the surface and space, and model simulations will lead to improvements in our understanding of the complex aerosol-related processes. For example, by integrating information on the aerosol mixing state and cloud properties, an overall picture of aerosol variability in terms of the physical and chemical properties and of the intricate aerosol-cloud interplay could be pieced together $[54,55]$.

Author Contributions: Data curation, M.P., D.C., J.C., A.S., J.S., J.T., and A.Z.; Formal analysis, L.K.B., M.P., J.S., H.T., and A.Z.; Funding acquisition, L.K.B. and J.F.; Methodology, E.K. and J.B.; Software, J.B. and C.F.; Supervision, J.F.; Visualization, E.K., M.P., and A.Z.; Writing—original draft, E.K.; Writing—review \& editing, L.K.B., M.P., J.B., J.S., A.Z., and J.F.

Funding: The ARM Aerial Facility team is gratefully acknowledged for the contribution collecting the aircraft data during TCAP which was supported by the Department of Energy (DOE) Atmospheric Radiation Measurement (ARM) Facility and Atmospheric System Research (ASR) Program. This research was supported by Office of Science of the U.S. Department of Energy as part of the ARM Facility and ASR Program. The Pacific Northwest National Laboratory is operated by Battelle Memorial Institute under contract DE-AC06-76RLO 1830.

Conflicts of Interest: The authors declare no conflict of interest.

\section{Appendix A. Contributions from Particles of Different Sizes to Scattering}

Similar to Kassianov et al. [19], we calculate the ambient scattering coefficient $\sigma_{\text {mod,adj }}$ at single wavelength $(0.55 \mu \mathrm{m})$ as a function of an assumed cut-off particle diameter $D^{*}$ (between 0.1 to $5 \mu \mathrm{m})$ to quantify contributions from particles of different sizes to the total scattering. Then we calculate normalized ambient scattering coefficient $\rho\left(D^{*}\right)=\sigma_{\bmod , a d j}\left(D^{*}\right) / \sigma_{\bmod , a d j}\left(D^{*}=5 \mu \mathrm{m}\right)$, which represents the relative contribution of particles with $D<D^{*}$ to the total scattering from all particles smaller than $5 \mu \mathrm{m}$. Figure A1a shows the mean and standard deviation for $\rho\left(D^{*}\right)$ computed for all 39 TCAP flight legs considered in this study (Section 2). Super-micron particles contribute noticeably to the total scattering in this case with $\rho\left(D^{*}\right)$ reaching about 0.81 for $D^{*}=1 \mu \mathrm{m}$ (Figure A1a). Note that there is a substantial (about three times) difference between the obtained winter contribution $(\sim 19 \%$, on average) and the corresponding summer contribution ( $7 \%$, on average).
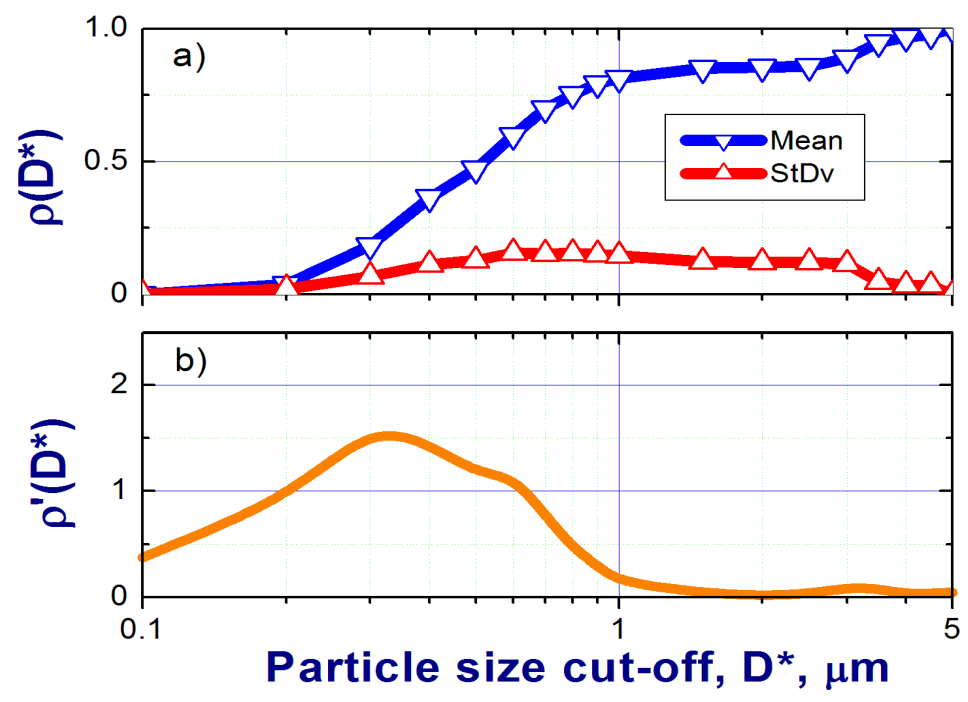

Figure A1. The normalized scattering coefficient (a) and its derivative (b) as a function of particle size cut-off. The blue line shows the mean for all TCAP flight legs and the red line represents the corresponding standard deviations. 
To further illustrate the relative contribution to $\sigma_{\text {mod, adj }}$ from different particle size ranges (for a given complex refractive index), we note that the relation for the ambient scattering coefficient can be rearranged as $\sigma_{\text {mod, }, a d j}=\int_{D_{\min }}^{D^{*}}\left(d \sigma_{\text {mod,adj }}(D) / d D\right) d D$, where $D_{\min } \sim 0.07 \mu \mathrm{m}$ [19]. Using this rearranged relation, we calculate the derivative of the normalized scattering coefficient as $\rho^{\prime}\left(D^{*}\right)=\sigma_{\text {mod, }, a d j}^{\prime}\left(D^{*}\right) / \sigma_{\text {mod, }, a d j}\left(D^{*}=5 \mu \mathrm{m}\right)$, where $\sigma_{\text {mod,adj }}^{\prime}(D)=d \sigma_{\text {mod,adj }}(D) / d D$. Figure A1b shows that on average particles in the size range between 0.3 and $0.4 \mu \mathrm{m}$ contribute mostly to the ambient scattering coefficient.

\section{References}

1. Esteve, A.R.; Highwood, E.J.; Ryder, C.L. A case study of the radiative effect of aerosols over Europe: EUCAARI-LONGREX. Atmos. Chem. Phys. 2016, 16, 7639-7651. [CrossRef]

2. Lacagnina, C.; Hasekamp, O.P.; Torres, O. Direct radiative effect of aerosols based on PARASOL and OMI satellite observations. J. Geophys. Res. 2017, 122, 2366-2388. [CrossRef]

3. Hand, J.L.; Gill, T.E.; Schichtel, B.A. Spatial and seasonal variability in fine mineral dust and coarse aerosol mass at remote sites across the United States. J. Geophys. Res. 2017, 122, 3080-3097. [CrossRef]

4. Hallar, A.G.; Molotch, N.P.; Hand, J.L.; Livneh, B.; McCubbin, I.B.; Petersen, R.; Michalsky, J.; Lowenthal, D.; Kunkel, K.E. Impacts of increasing aridity and wildfires on aerosol loading in the intermountain western US. Environ. Res. Lett. 2017, 12. [CrossRef]

5. Fast, J.D.; Gustafson, W.I., Jr.; Easter, R.C.; Zaveri, R.A.; Barnard, J.C.; Chapman, E.G.; Grell, G.A.; Peckham, S.E. Evolution of ozone, particulates, and aerosol direct radiative forcing in the vicinity of Houston using a fully coupled meteorology-chemistry-aerosol model. J. Geophys. Res. 2006, 111, D21305. [CrossRef]

6. Fiedler, S.; Stevens, B.; Mauritsen, T. On the sensitivity of anthropogenic aerosol forcing to model-internal variability and parameterizing a Twomey effect. J. Adv. Model. Earth Syst. 2017, 9, 1325-1341. [CrossRef]

7. Eck, T.F.; Holben, B.N.; Reid, J.S.; Sinyuk, A.; Dubovik, O.; Smirnov, A.; Giles, D.; O’Neill, N.T.; Tsay, S.C.; Ji, Q.; et al. Spatial and temporal variability of column-integrated aerosol optical properties in the southern Arabian Gulf and United Arab Emirates in summer. J. Geophys. Res. 2008, 113, D01204. [CrossRef]

8. Titos, G.; Jefferson, A.; Sheridan, P.J; Andrews, E.; Lyamani, H.; Alados-Arboledas, L.; Ogren, J.A. Aerosol light-scattering enhancement due to water uptake during TCAP campaign. Atmos. Chem. Phys. 2014, 14, 7031-7043. [CrossRef]

9. Kassianov, E.I.; Barnard, J.C.; Pekour, M.S.; Berg, L.K.; Michalsky, J.J.; Lantz, K.; Hodges, G.B. Do Diurnal Aerosol Changes Affect Daily Average Radiative Forcing? Geophys. Res. Lett. 2013, 40, 3265-3269. [CrossRef]

10. Berg, L.K.; Fast, J.D.; Barnard, J.C.; Burton, S.P.; Cairns, B.; Chand, D.; Comstock, J.M.; Dunagan, S.; Ferrare, R.A.; Flynn, C.J.; et al. The Two-Column Aerosol Project: Phase I-Overview and Impact of Elevated Aerosol Layers on Aerosol Optical Depth. J. Geophys. Res. 2016, 121, 336-361. [CrossRef]

11. Berg, L.K.; Fast, J.D.; Barnard, J.C.; Chand, D.; Comstock, J.M.; Pekour, M.; Sedlacek, A.J.; Shilling, J.E.; Tomlinson, J.M.; Zelenyuk, A.; et al. The Two-Column Aerosol Project: Phase II. J. Geophys. Res. 2018, in preparation.

12. Schuster, G.L.; Dubovik, O.; Holben, B.N. Angstrom exponent and bimodal aerosol size distributions. J. Geophys. Res. 2006, 111, D07207. [CrossRef]

13. Schmid, B.; Tomlinson, J.M.; Hubbe, J.M.; Comstock, J.M.; Mei, F.; Chand, D.; Pekour, M.S.; Kluzek, C.D.; Andrews, E.; Biraud, S.C.; et al. The DOE ARM Aerial Facility. Bull. Am. Meteor. Soc. 2014, 95, 723-742. [CrossRef]

14. Babu, S.S.; Nair, V.S.; Gogoi, M.M.; Moorthy, K.K. Seasonal variation of vertical distribution of aerosol single scattering albedo over Indian sub-continent: RAWEX aircraft observations. Atmos. Environ. 2016, 125, 312-323. [CrossRef]

15. Russell, P.B.; Kinne, S.A.; Bergstrom, R.W. Aerosol climate effects: Local radiative forcing and column closure experiments. J. Geophys. Res. 1997, 102, 9397-9407. [CrossRef]

16. Schmid, B.; Livingston, J.M.; Russell, P.B.; Durkee, P.A.; Jonsson, H.H.; Collins, D.R.; Flagan, R.C.; Seinfeld, J.H.; Gassó, S.; Hegg, D.A.; et al. Clear-sky closure studies of lower tropospheric aerosol and water vapor during ACE-2 using airborne sunphotometer, airborne in-situ, space-borne, and ground-based measurements. Tellus B 2000, 52, 568-593. [CrossRef] 
17. Malm, W.C.; Day, D.E.; Carrico, C.; Kreidenweis, S.M.; Collett, J.L., Jr.; McMeeking, G.; Lee, T.; Carrillo, J.; Schichtel, B. Intercomparison and closure calculations using measurements of aerosol species and optical properties during the Yosemite Aerosol Characterization Study. J. Geophys. Res. 2005, 110, D14302. [CrossRef]

18. Mack, L.A.; Levin, E.J.T.; Kreidenweis, S.M.; Obrist, D.; Moosmüller, H.; Lewis, K.A.; Arnott, W.P.; McMeeking, G.R.; Sullivan, A.P.; Wold, C.E.; et al. Optical closure experiments for biomass smoke aerosols. Atmos. Chem. Phys. 2010, 10, 9017-9026. [CrossRef]

19. Kassianov, E.; Berg, L.K.; Pekour, M.; Barnard, J.; Chand, D.; Flynn, C.; Ovchinnikov, M.; Sedlacek, A.; Schmid, B.; Shilling, J.; et al. Airborne Aerosol in Situ Measurements during TCAP: A Closure Study of Total Scattering. Atmosphere 2015, 6, 1069-1101. [CrossRef]

20. Allen, G.; Coe, H.; Clarke, A.; Bretherton, C.; Wood, R.; Abel, S.J.; Barrett, P.; Brown, P.; George, R.; Freitag, S.; et al. South East Pacific atmospheric composition and variability sampled along $20^{\circ} \mathrm{S}$ during VOCALS-Rex. Atmos. Chem. Phys. 2011, 11, 5237-5262. [CrossRef]

21. Kleinman, L.I.; Daum, P.H.; Lee, Y.-N.; Lewis, E.R.; Sedlacek, A.J., III; Senum, G.I.; Springston, S.R.; Wang, J.; Hubbe, J.; Jayne, J.; et al. Aerosol concentration and size distribution measured below, in, and above cloud from the DOE G-1 during VOCALS-REx. Atmos. Chem. Phys. 2012, 11, 207-223. [CrossRef]

22. Markowski, G.R. Improving Twomey's Algorithm for Inversion of Aerosol Measurement Data. Aerosol Sci. Technol. 1987, 7, 127-141. [CrossRef]

23. Collins, D.R.; Flagan, R.C.; Seinfeld, J.H. Improved inversion of scanning DMA data. Aerosol Sci. Technol. 2002, 36, 1-9. [CrossRef]

24. Jayne, J.T.; Leard, D.C.; Zhang, X.F.; Davidovits, P.; Smith, K.A.; Kolb, C.E.; Worsnop, D.R. Development of an aerosol mass spectrometer for size and composition analysis of submicron particles. Aerosol Sci. Technol. 2000, 33, 49-70. [CrossRef]

25. DeCarlo, P.F.; Kimmel, J.R.; Trimborn, A.; Northway, M.J.; Jayne, J.T.; Aiken, A.C.; Gonin, M.; Fuhrer, K.; Horvath, T.; Docherty, K.S.; et al. Field-deployable, high-resolution, time-of-flight aerosol mass spectrometer. Anal. Chem. 2006, 78, 8281-8289. [CrossRef] [PubMed]

26. Moteki, N.; Kondo, Y. Effects of mixing state on black carbon measurements by laser-induced incandescence. Aerosol Sci. Technol. 2007, 41, 398-417. [CrossRef]

27. Sedlacek, A.J., III; Lewis, E.R.; Kleinman, L.; Xu, J.; Zhang, Q. Determination of and evidence for non-core-shell structure of particles containing black carbon using the Single-Particle Soot Photometer (SP2). Geophys. Res. Lett. 2012, 39. [CrossRef]

28. Liu, P.; Ziemann, P.J.; Kittelson, D.B.; McMurry, P.H. Generating Particle Beams of Controlled Dimensions and Divergence: I. Theory of Particle Motion in Aerodynamic Lenses and Nozzle Expansions. Aerosol Sci. Technol. 1995, 22, 293-313. [CrossRef]

29. Zelenyuk, A.; Imre, D.; Wilson, J.; Zhang, Z.; Wang, J.; Mueller, K. Airborne Single Particle Mass Spectrometers (SPLAT II \& miniSPLAT) and new software for data visualization and analysis in a geo-spatial context. J. Am. Soc. Mass Spectrom. 2015, 26, 257-270. [PubMed]

30. Vaden, T.D.; Imre, D.; Beranek, J.; Zelenyuk, A. Extending the capabilities of single particle mass spectrometry: II. Measurements of aerosol particle density without DMA. Aerosol Sci. Technol. 2011, 45, 125-135. [CrossRef]

31. Pekour, M.S.; Schmid, B.; Chand, D.; Hubbe, J.M.; Kluzek, C.D.; Nelson, D.A.; Tomlinson, J.M.; Cziczo, D.J. Development of a new airborne humidigraph system. Aerosol Sci. Technol. 2013, 47, 201-207. [CrossRef]

32. Shinozuka, Y.; Johnson, R.R.; Flynn, C.J.; Russell, P.B.; Schmid, B.; Redemann, J.; Dunagan, S.E.; Kluzek, C.D.; Hubbe, J.M.; Segal-Rosenheimer, M.; et al. Hyperspectral aerosol optical depths from TCAP flights. J. Geophys. Res. Atmos. 2013, 118, 12180-12194. [CrossRef]

33. Anderson, T.L.; Ogren, J.A. Determining aerosol radiative properties using the TSI 3563 Integrating Nephelometer. Aerosol Sci. Technol. 1998, 29, 57-69. [CrossRef]

34. Hallar, A.G.; Strawa, A.W.; Schmid, B.; Andrews, E.; Ogren, J.; Sheridan, P.; Ferrare, R.; Covert, D.; Elleman, R.; Jonsson, H.; et al. Atmospheric Radiation Measurements Aerosol Intensive Operating Period: Comparison of aerosol scattering during coordinated flights. J. Geophys. Res. 2006, 111, D05S09. [CrossRef]

35. Weber, R.J.; Clarke, A.D.; Litchy, M.; Li, J.; Kok, G.; Schillawski, R.D.; McMurry, P.H. Spurious aerosol measurements when sampling from aircraft in the vicinity of clouds. J. Geophys. Res. 1998, 103, 28337-28346. [CrossRef] 
36. Smirnov, A.; Sayer, A.M.; Holben, B.N.; Hsu, N.C.; Sakerin, S.M.; Macke, A.; Nelson, N.B.; Courcoux, Y.; Smyth, T.J.; Croot, P.; et al. Effect of wind speed on aerosol optical depth over remote oceans, based on data from the Maritime Aerosol Network. Atmos. Meas. Tech. 2012, 5, 377-388. [CrossRef]

37. Particle-into-Liquid Sampler Instrument Handbook. Available online: https:/ /www.arm.gov / publications / tech_reports/handbooks/pils_handbook.pdf (accessed on 11 June 2018).

38. Seinfeld, J.H.; Pandis, S.N. Atmospheric Chemistry and Physics: From Air Pollution to Climate Change; John Wiley and Sons Ltd.: Hoboken, NJ, USA, 2016.

39. Esteve, A.R.; Highwood, E.J.; Morgan, W.T.; Allen, G.; Coe, H.; Grainger, R.G.; Brown, P.; Szpek, K. A study on the sensitivities of simulated aerosol optical properties to composition and size distribution using airborne measurements. Atmos. Environ. 2014, 89, 517-524. [CrossRef]

40. Hu, D.; Chen, J.; Ye, X.; Li, L.; Yang, X. Hygroscopicity and evaporation of ammonium chloride and ammonium nitrate: Relative humidity and size effects on the growth factor. Atmos. Environ. 2011, 45, 2349-2355. [CrossRef]

41. Healy, R.M.; Evans, G.J.; Murphy, M.; Jurányi, Z.; Tritscher, T.; Laborde, M.; Weingartner, E.; Gysel, M.; Poulain, L.; Kamilli, K.A.; et al. Predicting hygroscopic growth using single particle chemical composition estimates. J. Geophys. Res. Atmos. 2014, 119, 9567-9577. [CrossRef]

42. Xie, Y.S.; Li, Z.Q.; Zhang, Y.X.; Zhang, Y.; Li, D.H.; Li, K.T.; Xu, H.; Wang, Y.Q.; Chen, X.F.; Schauer, J.J.; Bergin, M. Estimation of atmospheric aerosol composition from ground-based remote sensing measurements of Sun-sky radiometer. J. Geophys. Res. Atmos. 2017, 122, 498-518. [CrossRef]

43. Marshall, J.; Lohmann, U.; Leaitch, W.R.; Lehr, P.; Hayden, K. Aerosol scattering as a function of altitude in a coastal environment. J. Geophys. Res. 2007, 112, D14203. [CrossRef]

44. Zieger, P.; Fierz-Schmidhauser, R.; Poulain, L.; Müller, T.; Birmili, W.; Spindler, G.; Wiedensohler, A.; Baltensperger, U.; Weingartner, E. Influence of water uptake on the aerosol particle light scattering coefficients of the Central European aerosol. Tellus B 2014, 66, 22716. [CrossRef]

45. Barnard, J.C.; Fast, J.D.; Paredes-Miranda, G.; Arnott, W.P.; Laskin, A. Technical note: Evaluation of the WRF-Chem "Aerosol chemical to aerosol optical properties" module using data from the MILAGRO campaign. Atmos. Chem. Phys. 2010, 10, 7325-7340. [CrossRef]

46. Pilinis, C.; Charalampidis, P.E.; Mihalopoulos, N.; Pandis, S.N. Contribution of particulate water to the measured aerosol optical properties of aged aerosol. Atmos. Environ. 2014, 82, 144-153. [CrossRef]

47. Wex, H.; Neususs, C.; Wendisch, M.; Stratmann, F.; Koziar, C.; Keil, A.; Wiedensohler, A.; Ebert, M. Particle scattering, backscattering, and absorption coefficients: An in situ closure and sensitivity study. J. Geophys. Res. Atmos. 2012, 107, 8122. [CrossRef]

48. York, D.; Evensen, N.M.; Lopez Martinez, M.; de Basabe Delgado, J. Unified equations for the slope, intercept, and standard errors of the best straight line. Am. J. Phys. 2004, 72, 367-375. [CrossRef]

49. Zelenyuk, A.; Imre, D.; Han, J.H.; Oatis, S. Simultaneous measurements of individual ambient particle size, composition, effective density, and hygroscopicity. Anal. Chem. 2008, 80, 1401-1407. [CrossRef] [PubMed]

50. Zelenyuk, A.; Imre, D.; Earle, M.; Easter, R.; Korolev, A.; Leaitch, R.; Liu, P.; Macdonald, A.M.; Ovchinnikov, M.; Strapp, W. In Situ Characterization of Cloud Condensation Nuclei, Interstitial, and Background Particles Using the Single Particle Mass Spectrometer, SPLAT II. Anal. Chem. 2010, 82, 7943-7951. [CrossRef] [PubMed]

51. Friedman, B.; Zelenyuk, A.; Beranek, J.; Kulkarni, G.; Pekour, M.; Gannet Hallar, A.; McCubbin, I.B.; Thornton, J.A.; Cziczo, D.J. Aerosol measurements at a high-elevation site: Composition, size, and cloud condensation nuclei activity. Atmos. Chem. Phys. 2013, 13, 11839-11851. [CrossRef]

52. Seinfeld, J.H.; Bretherton, C.; Carslaw, K.S.; Coe, H.; DeMott, P.J.; Dunlea, E.J.; Feingold, G.; Ghan, S.; Guenther, A.B.; Kahn, R.; et al. Improving our fundamental understanding of the role of aerosol-cloud interactions in the climate system. Proc. Natl. Acad. Sci. USA 2016, 113, 5781-5790. [CrossRef] [PubMed]

53. Shinozuka, Y.; Redemann, J.; Livingston, J.M.; Russell, P.B.; Clarke, A.D.; Howell, S.G.; Freitag, S.; O'Neill, N.T.; Reid, E.A.; Johnson, R.; et al. Airborne observation of aerosol optical depth during ARCTAS: Vertical profiles, inter-comparison and fine-mode fraction. Atmos. Chem. Phys. 2011, 11, 3673-3688. [CrossRef] 
54. Ching, J.; Fast, J.D.; West, M.; Riemer, N.R. Metrics to quantify the importance of mixing state for CCN activity. Atmos. Chem. Phys. 2017, 17, 7445-7458. [CrossRef]

55. Ching, J.; Zaveri, R.A.; Easter, R.C.; Riemer, N.; Fast, J.D. A three-dimensional sectional representation of aerosol mixing state for simulating optical properties and cloud condensation nuclei. J. Geophys. Res. 2016, 121, 5912-5929. [CrossRef] 